\title{
Benzodiazepine use and risk of Alzheimer's disease: case-control study
}

\author{
(c) $\underset{1}{(1)(8)}$ OP DeN ACCESS
}

\author{
Sophie Billioti de Gage PhD student ${ }^{1}$, Yola Moride professor ${ }^{23}$, Thierry Ducruet researcher ${ }^{2}$, Tobias \\ Kurth director of research ${ }^{45}$, Hélène Verdoux professor ${ }^{16}$, Marie Tournier associate professor ${ }^{16}$, \\ Antoine Pariente associate professor ${ }^{1}$, Bernard Bégaud professor ${ }^{1}$
}

${ }^{1}$ INSERM, U657-Pharmacoepidemiology, Université de Bordeaux, F-33000 Bordeaux, France; ${ }^{2}$ Research Center, University of Montreal Hospital Center, Montreal, Canada; ${ }^{3}$ Faculty of Pharmacy, University of Montreal, Montreal, Canada; ${ }^{4}$ Inserm Research Center for Epidemiology and Biostatistics, U897-Team Neuroepidemiology, F-33000 Bordeaux, France; ${ }^{5}$ University of Bordeaux, College of Health Sciences, F-33000 Bordeaux, France; ${ }^{6}$ Centre Hospitalier Charles Perrens, F-33000 Bordeaux, France

\begin{abstract}
Objectives To investigate the relation between the risk of Alzheimer's disease and exposure to benzodiazepines started at least five years before, considering both the dose-response relation and prodromes (anxiety, depression, insomnia) possibly linked with treatment.

Design Case-control study.

Setting The Quebec health insurance program database (RAMQ).

Participants 1796 people with a first diagnosis of Alzheimer's disease and followed up for at least six years before were matched with 7184 controls on sex, age group, and duration of follow-up. Both groups were randomly sampled from older people (age $>66$ ) living in the community in 2000-09.
\end{abstract}

Main outcome measure The association between Alzheimer's disease and benzodiazepine use started at least five years before diagnosis was assessed by using multivariable conditional logistic regression. Ever exposure to benzodiazepines was first considered and then categorised according to the cumulative dose expressed as prescribed daily doses $(1-90,91-180,>180)$ and the drug elimination half life.

Results Benzodiazepine ever use was associated with an increased risk of Alzheimer's disease (adjusted odds ratio 1.51, 95\% confidence interval 1.36 to 1.69 ; further adjustment on anxiety, depression, and insomnia did not markedly alter this result: $1.43,1.28$ to 1.60$)$. No association was found for a cumulative dose $<91$ prescribed daily doses. The strength of association increased with exposure density (1.32 (1.01 to 1.74 ) for $91-180$ prescribed daily doses and 1.84 (1.62 to 2.08 ) for $>180$ prescribed daily doses) and with the drug half life (1.43 (1.27 to 1.61) for short acting drugs and 1.70 (1.46 to 1.98) for long acting ones).

Conclusion Benzodiazepine use is associated with an increased risk of Alzheimer's disease. The stronger association observed for long term exposures reinforces the suspicion of a possible direct association, even if benzodiazepine use might also be an early marker of a condition associated with an increased risk of dementia. Unwarranted long term use of these drugs should be considered as a public health concern.

\section{Introduction}

Dementia is currently the main cause of dependency in older people and a major public health concern affecting about 36 million people worldwide. ${ }^{1}$ Because of population growth and demographic ageing, this number is expected to double every 20 years and to reach 115 million in 2050, ${ }^{1}$ resulting in tragic human consequences and social costs. ${ }^{2.4}$ As there are no effective treatments, the search for putative modifying factors remains a priority. Several studies have shown that benzodiazepine use could be one of these..$^{5-9}$ This class of drugs is mainly used to treat anxiety or insomnia. ${ }^{10}$ Prevalence of use among elderly patients is consistently high in developed countries and ranges from $7 \%$ to $43 \%{ }^{11-14}$ International guidelines ${ }^{10}$ recommend short term use, mainly because of withdrawal symptoms that make discontinuation problematic. Although the long term effectiveness of benzodiazepines remains unproved for insomnia ${ }^{15-18}$ and questionable for anxiety, ${ }^{15}$ their use is predominantly chronic in older people. ${ }^{19} 20$

While the acute deleterious effects of benzodiazepines on memory and cognition are well documented, ${ }^{21-24}$ the possibility of an increased risk of dementia is still a matter of debate. The frequency of symptoms highly correlated with prescription of benzodiazepines (anxiety, insomnia, and depressive disorders) increases in the years before a diagnosis of dementia. ${ }^{25-28}$ Hence, benzodiazepines might not cause the disease but rather be prescribed to treat its prodromes. Adjustment for such a reverse causality bias is not easy in observational studies as prodromes are often not recorded as such. It might consist in the demonstration of a delayed risk ${ }^{9}$ or in the censoring of information on exposures started during the suspected prodromal 
phase. Moreover, few studies published on the topic have had sufficient power to investigate a cumulative dose relation, which is a compelling argument in the assessment of a potentially drug induced outcome.

We evaluated the association between past benzodiazepine use and the risk of Alzheimer's disease using an administrative claims database with a long follow-up period and investigated the potential dose-effect relation.

\section{Methods}

\section{Study design and setting}

We carried out a case-control study among older people (age >66) living in the community in the province of Quebec (Canada) and who were members of the public drug plan from 1 January 2000 to 31 December 2009. In Quebec, nearly all older people (about $98 \%$ ) are covered by the drug plan. Data sources for the study consisted of the prescription and medical services recorded in an administrative claims database (RAMQ). The source population included random samples of 38741 people with a diagnosis or treatment (such as cholinesterase inhibitors or memantine) related to dementia for cases and 86 259 people without these conditions for controls.

\section{Selection of cases and controls}

People were eligible for inclusion as cases for the study if they met the following criteria: a first diagnosis (index date) of Alzheimer's disease (ICD-9 (international classification of disease, ninth revision) 331.0) recorded during the study period without any record of another type of dementia at the index date or before; absence of any anti-dementia treatment before index date; and at least six years of follow-up before the index date. Each person with dementia (case) was matched on sex, age group (70-74, 75-79, 80-84, or $\geq 85$ ), and duration of follow-up $(6,7,8,9$, or 10 years) at the index date with four controls by using an incidence density sampling strategy.

\section{Exposure assessment}

Benzodiazepine use was assessed with dispensation claims recorded in the RAMQ database. We considered all benzodiazepines included in the RAMQ list of reimbursed drugs during the study period (table $1 \Downarrow$ ). Treatments initiated less than five years before the index date were not considered as this could convey a reverse causality bias. Therefore, exposure was ascertained in a time window ranging from five to 10 years (maximum duration of follow-up) before the index date.

Exposure was described according to three criteria:

- Ever use: at least one claim for a benzodiazepine during the above defined time window

- Cumulative dose: in the absence of an indisputable hypothesis about the pathophysiological mechanism possibly involved, we used the cumulative dose as it combined both the duration of treatment and the somewhat variable daily dose. For each person and each product, we computed the cumulative dose used during the study time window and converted it into a number of prescribed daily doses (PDDs) by dividing it by the average daily dose for this product in the source cohort. ${ }^{29}$ Therefore, one PDD corresponded to an average one day exposure. Three cumulative dose categories were considered: 1-90 PDDs- that is, cumulative exposure $\leq 3$ months 91-180 PDDs-3-6 months $>180$ PDDs $\longrightarrow 6$ months (long term users)
- Drug elimination half life: people were categorised as users of short ( $<20$ hours) or long acting benzodiazepines. When different molecules were used by the same person, the longer half life was retained (table 1).

People without any claim for benzodiazepines during the study time window were categorised as non-users and served as reference for the analyses.

To conduct a sensitivity analysis, we pushed the index date back one year to take into account a potential delay between the onset of disease and the recording of diagnosis in the RAMQ database. The exposure time window then became the period between 6 and 10 years prior to diagnosis (index date).

\section{Potential confounders}

Covariates other than those used for matching cases and controls - that is, sex, age, duration of follow-up-were measured during the same time window as exposure to benzodiazepines (between five and up to 10 years before the index date in the main analysis and between six and up to 10 years before this date in the sensitivity analysis). Potential confounders ${ }^{30-33}$ included high blood pressure (diagnosis based on ICD-9 codes 401.0, 401.1, 401.9, 402.0, 402.1, 402.9, 403.0, $403.1,403.9,404.0,404.1$, and 404.9 or use of antihypertensive drugs), myocardial infarction (ICD-9 codes 410, 412), stroke (ICD-9 codes 431, 432.0, 432.1, 432.9, 436, 437), use of platelet inhibitors or oral anticoagulants, hypercholesterolaemia (ICD-9 codes 272.0 or use of lipid lowering drugs), diabetes mellitus (ICD-9 codes 250 or use of antidiabetic drugs), anxiety (ICD-9 codes 300.0, 300.2, 300.3), depression (ICD-9 codes 296.2, 296.3, 300.4, 311), and insomnia (ICD-9 codes 307.4, 327.3, $327.4,780.5)$. Other diagnoses included those of the Charlson comorbidity index ${ }^{34}$ validated for administrative claim databases ${ }^{35}$ : chronic pulmonary disease, rheumatic disease, peptic ulcer, hemiplegia or paraplegia, renal disease, malignancy or metastatic solid tumour, liver disease, and AIDS/HIV. We created a broad category of "comorbidity" that included patients with at least one diagnostic claim for the above diagnoses.

\section{Statistical analysis}

Characteristics of cases and controls were described with numbers and percentages. We assessed the association between Alzheimer's disease and benzodiazepine exposure through multivariable conditional logistic regression analysis, the diagnosis of Alzheimer's disease being the dependent variable and benzodiazepine use the main independent variable. Models were adjusted for the covariates listed above. At first, we did not include depression, anxiety, and insomnia in the models as the nature of their association with dementia (risk factor or prodrome) is debated, ${ }^{36-43}$ and their a priori strong correlation with benzodiazepine exposure ${ }^{33}{ }^{44}$ could result in an overadjustment (model 1). Subsequently we added them into the models if they did not interact with exposure (model 2). To test for significant effect modification, we used the likelihood ratio test contrasting the main model to a model including appropriate interaction terms.

Analyses were conducted with the SAS statistical package (SAS 9.3 for Windows). All reported $\mathrm{P}$ values are two tailed, with $\mathrm{P}<0.05$ defining significance. 


\section{Results}

\section{Study population}

We identified 1796 people as cases (figure $\Downarrow$ ) and matched them with 7184 controls, both groups being followed up for at least six years before the index date.

\section{Main analysis}

During the study period, 894 people with Alzheimer's disease (49.8\%) and 2873 controls (40.0\%) had ever used benzodiazepines; the treatment was still active at the date of the diagnosis of dementia in $64.8 \%$ of cases and $60.6 \%$ of controls. The proportion of cumulative exposures of six or fewer months (that is, $\leq 180$ prescribed daily doses (PDDs)) did not substantially differ between the groups. Conversely, long term use (that is, $>180$ PDDs or cumulative exposure over six months) was markedly more common among people with Alzheimer's disease $(32.9 \%)$ than controls $(21.8 \%)$. The excess of benzodiazepine use in cases concerned products with both short $(32.6 \% v 27.8 \%)$ and long half life $(17.2 \% v 12.2 \%)$. A history of myocardial infarction was less common among people with Alzheimer's disease than controls (3.4\% v 4.6\%). The opposite was found for stroke ( $7.0 \% v 5.8 \%)$, hypercholesterolaemia $(20.9 \% v 16.5 \%)$, and anxiety $(21.4 \% v 15.1 \%)$. No difference was observed for the other covariates (table $2 \Downarrow$ ).

Use of benzodiazepines at any time was significantly associated with an increased risk of Alzheimer's disease (adjusted odds ratio $1.51,95 \%$ confidence interval 1.36 to 1.69 ). No difference was found for cumulative exposures of up to three months - that is, 1-90 PDDs (1.09, 0.92 to 1.28). For longer uses, the risk increased with cumulative exposure: 1.32 (1.01 to 1.74$)$ for three to six months (91-180 PDDs) and 1.84 (1.62 to 2.08) for more than six months (>180 PDDs) (table $3 \Downarrow$ ). The association with Alzheimer's disease was stronger for long acting benzodiazepines $(1.70,1.46$ to 1.98$)$ than for short acting ones $(1.43,1.27$ to 1.61$)$ (table $3 \Downarrow)$.

We found no significant interaction for anxiety $(\mathrm{P}=0.48)$, depression $(\mathrm{P}=0.75)$, or insomnia $(\mathrm{P}=0.99)$. Further adjustment on these variables did not markedly alter the results (table $3 \Downarrow$ ).

\section{Sensitivity analysis}

When we pushed the index date back one year (excluding information on benzodiazepine use during the six years before the index date), the association between benzodiazepines and Alzheimer's disease remained unchanged, whatever the classification of exposure. Adjusted odds ratios were $1.50(95 \%$ confidence interval 1.35 to 1.68$)$ for ever use, 1.11 (0.94 to 1.30 ) for up to three months' use; 1.56 (1.21 to 2.01) for three to six months' use; and 1.79 (1.58 to 2.04) for more than six months' exposure. Again, further adjustment on anxiety, depression, and insomnia did not change the conclusions.

\section{Discussion}

This case-control study based on 8980 individuals representative of elderly people living in the community in Quebec showed that the risk of Alzheimer's disease was increased by $43-51 \%$ among those who had used benzodiazepines in the past. Risk increased with density of exposure and when long acting benzodiazepines were used. Further adjustment on symptoms thought to be potential prodromes for dementia-such as depression, anxiety, or sleep disorders-did not meaningfully alter the results.

\section{Comparison with other studies}

Our findings are congruent with those of five previous studies, ${ }^{5-9}$ two of which explored the modifying effect of the dose used. ${ }^{56}$ In four studies, the role of a putative protopathic bias could not be ruled out because an insufficient duration of follow-up ${ }^{5}$; a lack of statistical power in subgroup analyses ${ }^{8}$; and no consideration of the most relevant time window for exposure and ascertainment of confounders. ${ }^{6}$ The most recent study found a similar 50\% increased risk within the 15 years after the start of benzodiazepine use (average length of follow-up 6.2 years). ${ }^{9}$ This excess risk was delayed and thus not indicative of a reverse causality bias. Another study found a positive association, though lacked significance because of its limited sample size. ${ }^{45}$ The earliest work observed a paradoxical protective effect of benzodiazepines, which could be partly explained by the misclassification of past users as a part of the reference group. ${ }^{46}$

\section{Strengths and limitations}

Our study was designed specifically to reduce the possibility of reverse causation bias and to provide additional arguments linking benzodiazepine use with Alzheimer's disease, such as a dose-effect relation.

Firstly, we assessed benzodiazepine treatments initiated more than five years (six years in the sensitivity analysis) before the diagnosis of Alzheimer's disease, a period when prescriptions were less likely to be motivated by the prodromes of the disease. This allowed better control for reverse causation bias, as did further adjustment on anxiety, depression, and insomnia, which did not alter the strength or the significance of the association. A second added value of our study was the exploration of a possible dose-effect relation, a criterion necessary to establish robust links between benzodiazepine use and risk of Alzheimer's disease. ${ }^{47}$ The risk associated with the lowest cumulative levels of exposure (<90 prescribed daily doses (PDDs)) did not differ from that seen in controls, while the risk was increased by $32 \%$ and $84 \%$ for 91-180 PDDs and >180 PDDs, respectively. The higher odds ratio associated with long acting benzodiazepines (half life $\geq 20$ hours) also argues in favour of a dose-response effect. Indeed, unlike products with short half lives, these molecules used daily result in more or less constant blood and brain active concentrations.

Finally, our study population was representative of older people of Quebec, which makes the findings generalisable.

The limitations of the study are shared with other studies that use claims databases without direct access to patients. As case ascertainment was based on diagnoses recorded in claims data, misclassification was possible, even if diagnoses were always made by a physician (general practitioner, neurologist, internist, or geriatrician). Similarly, there could have been a delay between the actual date of onset of Alzheimer's disease and the date of its recording (index date for our study).

In the Quebec public drug plan, treatments with cholinesterase inhibitors are reimbursed only for patients having a mini-mental state examination score ${ }^{48}$ ranging between 10 and 26 at initiation. Furthermore, maintenance of reimbursement after a course of treatment of six months requires both an absence of notable worsening and an improvement in at least one cognitive function. These criteria, fulfilled in $72 \%$ of patients with Alzheimer's disease in this study, clearly imply the repeated use of validated diagnostic tools. For this reason, diagnostic misclassification was unlikely to be a major concern. Moreover, misclassification of some unaffected people as cases and some cases as controls would reduce the exposure difference between the groups, making the estimates more conservative. 
In regard to a possible delay in recording a diagnosis of Alzheimer's disease, one should note that pushing back the index date by one year in the sensitivity analysis did not alter the results.

It could also be argued that benzodiazepine use might confound the clinical diagnosis of dementia by impairing cognitive functions. This seems unlikely as odds ratios in those who used benzodiazepines for more than six months were 1.72 (95\% confidence interval 1.51 to 1.97 ) and 2.51 (1.97 to 3.20) for treatments still underway at the date of diagnosis or discontinued for at least one year before, respectively.

We compared exposure on the basis of information recorded in the database without the possibility of ascertaining whether the dates of benzodiazepine claims corresponded to their actual consumption. Nevertheless, the excess risk found in our study concerned only long term treatments that required multiple refilled prescriptions, which does not support non-compliance. Therefore, observed long lasting uses were likely to correspond to actual exposures.

Neuropsychiatric symptoms used for adjustment—such as anxiety, depression, and sleep disorders - could have been under-reported if they were not considered by the physician as a main diagnosis. This limitation, which is common to other databases widely used in pharmacoepidemiology, could be deleterious only if it is notable and not balanced across the groups. Moreover, in our study sample, anxiety was recorded in $21.4 \%$ of cases and $15.1 \%$ of controls; for depression, percentages were $2.9 \%$ and $2.4 \%$, respectively. These figures do not seem to depart markedly from prevalences found in the literature for people aged $>65 .{ }^{49} 50$

The RAMQ database does not contain information on socioeconomic status, education level, smoking habits, or alcohol consumption. Smoking and alcohol consumption are known to be associated with benzodiazepine use but not a priori with Alzheimer type dementia, even if chronic wine consumption has been claimed to be a protective factor. ${ }^{51}$ The effect of not adjusting for these factors was likely to be conservative as benzodiazepine use is thought to be higher in regular wine and alcohol consumers. ${ }^{52}$ Socioeconomic and educational levels have been shown to be inversely correlated with the risk of presenting with dementia, ${ }^{31} 5354$ and thus lack of adjustment for these factors could results in bias. Their association with benzodiazepine use, however, remains unclear as it has been reported as absent, ${ }^{44}$ positive, ${ }^{55}$ or negative. ${ }^{56} 57$

Finally, we cannot rule out alternative hypotheses. For example, anxiety and sleep disorders, two of the main indications for benzodiazepines, could be associated with early $\beta$ amyloid lesions in brain, ${ }^{42}{ }^{58}$ and persistent mid-life anxiety could be associated with a greater risk of dementia in older people. ${ }^{40}$ Therefore, benzodiazepine use might be an early marker of a condition associated with an increased risk of dementia and not the cause.

\section{Biological plausibility}

The deleterious effects of benzodiazepines on memory are well documented. ${ }^{22}{ }^{23}$ No univocal pathophysiological mechanism, however, can be reasonably advanced to explain an increased risk of dementia. Recently, a systematic review underlined that benzodiazepine use induces both non-amnestic and amnestic mild cognitive impairment ${ }^{59}$; a faster progression of Alzheimer's disease being observed in the latter form. ${ }^{60}{ }^{61}$ Chronic administration of benzodiazepines also induces a down-regulation of their binding receptors, ${ }^{62}$ and a reduction in the number of these receptors seems to be correlated with cognitive decline. ${ }^{63}$

Under a causal assumption, the most plausible hypothesis would be the limitation in cognitive reserve capacity ${ }^{64}$ induced by the long term use of benzodiazepines, which might reduce a person's ability to cope with early phase brain lesions by soliciting accessory neuronal networks. A unique approach to further investigation of causality would be, if feasible, to turn to experimental animal models in an attempt to identify a possible biological mechanism.

\section{Implications for clinical practice and public health}

Benzodiazepines are indisputably valuable tools for managing anxiety disorders and transient insomnia. As stated in international guidelines, however, treatments should be of short duration and not exceed three months.

Our study reinforces the suspicion of an increased risk of Alzheimer type dementia among benzodiazepine users, particularly long term users, and provides arguments for carefully evaluating the indications for use of this drug class. Our findings are of major importance for public health, especially considering the prevalence and chronicity of benzodiazepine use in older people and the high and increasing incidence of dementia in developed countries. In such conditions, a risk increased by $43-51 \%$ in users would generate a huge number of excess cases, even in countries where the prevalence of use of these drugs is not high.

To date, no preventive or curative treatment has been shown to be satisfactorily effective in Alzheimer's disease. For this reason, the search for putative alterable risk factors should be prioritised. Long term use of benzodiazepines and related drugs (such as other anxiolytics and hypnotics) could be a candidate because their association with Alzheimer's disease is at least plausible and this factor is typically alterable as only use over three months (that is, outside international recommendations and without a priori therapeutic justification) seems to be associated with an excess risk. This putative impact, added to other adverse consequences such as fractures related to falls, ${ }^{65}$ should be seriously considered by regulatory agencies and prescribers. In view of the evidence, it is now crucial to encourage physicians to carefully balance the benefits and risks when initiating or renewing a treatment with benzodiazepines and related products in older patients. Despite the lack of data in younger adults, the precautionary principle would also support extending that recommendation to them.

\section{Unanswered questions and future research}

Experimental animal or cellular models are needed to help in identifying a possible biological mechanism linking benzodiazepines with risk of Alzheimer's disease. Studies based on a long follow-up - that is, at least 20-30 years-would make it possible to evaluate the risk of long term use of benzodiazepines in younger adults and to better assess the exact role of anxiety, sleep disorders, and depression as putative early risk factors of future dementia.

Contributors: SB, BB, YM, AP, HV, and TK contributed to the conception and design of the study. TD and YM contributed to data acquisition. SB and TD did the statistical analyses. All authors contributed to interpretation of the results. SB and BB drafted the manuscript. All authors critically revised the manuscript for important intellectual content. SB and TD had full access to all of the study data and take responsibility for the integrity of the data and the accuracy of the data analysis. TK 


\section{What is already known on this topic}

In developed countries benzodiazepine use remains highly prevalent and is often chronic in older people despite the recommendations Although an increased risk of dementia has been identified in benzodiazepine users, the nature of this association, whether causal or not, remains unclear

\section{What this study adds}

There is a dose-effect relation between benzodiazepine use and increased risk of Alzheimer's disease in older people treated previously for more than three months, with the risk being higher for long acting formulations

Whether causal or not, the nature of the link cannot be definitively established: benzodiazepine use might also be an early marker of a condition associated with an increased risk of dementia

Benzodiazepine prescription in older people should comply with good practice guidelines-that is, the shortest duration with a preference for formulations with a short half life

and BB supervised the study. All the authors made a significant contribution to the research and the development of the manuscript and approved the final version for publication. SB and BB are guarantors.

Funding: This research was conducted by the INSERM (Institut National de la Santé et de la Recherche Médicale) and University of Bordeaux. Additional support was provided by unconditional grants from IRESP (Institut de Recherche en Santé Publique); the French Ministry of Health (Direction Générale de la Santé); and the Funding Agency for Health Research of Quebec (Fonds de la Recherche en Santé du Québec, FRSQ).

Competing interests: All authors have completed the Unified Competing Interest form at http://www.icmje.org/coi_disclosure.pdf (available on request from the corresponding author) and declare that TK has received investigator-initiated research funding from the French National Research Agency and the US National Institutes of Health within the past two years and honorariums from $B M J$ and Cephalalgia for editorial services; MT received honorariums as a speaker from Astra Zeneca, BMS, and Janssen; AP participated in studies conducted by the Clinical Research Center of the Bordeaux Teaching Hospital and funded by Novartis, Sanofi-Aventis, Lundbeck, and Vivatech, none of which were related to the present study.

Ethical approval: Protocol was approved by the research ethics committee of the Research Center of the University of Montreal Hospital Center (CRCHUM).

Data sharing: No additional data available.

Transparency declaration: SB and BB affirm that the manuscript is an honest, accurate, and transparent account of the study being reported; that no important aspects of the study have been omitted; and that any discrepancies from the study as planned have been explained.

World Alzheimer Report 2009. Alzheimer Disease International, 2009.

2 Dementia: a public health priority. World Health Organization, 2012

3 Leicht $\mathrm{H}$, Heinrich $\mathrm{S}$, Heider D, Bachmann $\mathrm{C}$, Bickel $\mathrm{H}$, van den Bussche $\mathrm{H}$, et al. Net costs of dementia by disease stage. Acta Psychiatr Scand 2011;124:384-95.

4 Fineberg NA, Haddad PM, Carpenter L, Gannon B, Sharpe R, Young AH, et al. The size, burden and cost of disorders of the brain in the UK J Psychopharmacol 2013.27:761-70.

5 Wu CS, Wang SC, Chang IS, Lin KM. The association between dementia and long-term use of benzodiazepine in the elderly: nested case-control study using claims data. Am J Geriatr Psychiatry 2009;17:614-20.

6 Wu CS, Ting TT, Wang SC, Chang IS, Lin KM. Effect of benzodiazepine discontinuation on dementia risk. Am J Geriatr Psychiatry 2011;19:151-9.

7 Lagnaoui R, Begaud B, Moore N, Chaslerie A, Fourrier A, Letenneur L, et al. Benzodiazepine use and risk of dementia: a nested case-control study. $J$ Clin Epidemiol 2002:55:314-8.

8 Gallacher J, Elwood P, Pickering J, Bayer A, Fish M, Ben-Shlomo Y. Benzodiazepine use and risk of dementia: evidence from the Caerphilly Prospective Study (CaPS). J Epidemio Community Health 2012;66:869-73.

9 Billioti de Gage S, Begaud B, Bazin F, Verdoux H, Dartigues JF, Peres K, et al. Benzodiazepine use and risk of dementia: prospective population based study. BMJ 2012:345:e6231.

10 European Medicines Agency. Summary of product characteristics for benzodiazepines as anxiolytics or hypnotics. EMA, 1994.

11 Donoghue J, Lader M. Usage of benzodiazepines. A review. Int J Psychiatry in Clin Pract 2010;14:78-87.

12 Dell'osso B, Lader M. Do benzodiazepines still deserve a major role in the treatment of psychiatric disorders? A critical reappraisal. Eur Psychiatry 2013;28:7-20.

13 Cheng JS, Huang WF, Lin KM, Shih YT. Characteristics associated with benzodiazepine usage in elderly outpatients in Taiwan. Int J Geriatr Psychiatry 2008;23:618-24.

14 Paulose-Ram R, Safran MA, Jonas BS, Gu Q, Orwig D. Trends in psychotropic medication use among U.S. adults. Pharmacoepidemiol Drug Saf 2007;16:560-70.
15 Vinkers $\mathrm{CH}$, Olivier $\mathrm{B}$. Mechanisms underlying tolerance after long-term benzodiazepine use: a future for subtype-selective GABA(A) receptor modulators? Adv Pharmacol Sci 2012;2012:416864.

16 Poyares D, Guilleminault C, Ohayon MM, Tufik S. Chronic benzodiazepine usage and withdrawal in insomnia patients. J Psychiatr Res 2004:38:327-34.

17 Monane M, Glynn RJ, Avorn J. The impact of sedative-hypnotic use on sleep symptoms in elderly nursing home residents. Clin Pharmacol Ther 1996;59:83-92.

18 Curran HV, Collins R, Fletcher S, Kee SC, Woods B, lliffe S. Older adults and withdrawal from benzodiazepine hypnotics in general practice: effects on cognitive function, sleep, mood and quality of life. Psychol Med 2003;33:1223-37.

19 Neutel $\mathrm{Cl}$. The epidemiology of long-term benzodiazepine use. Int Rev Psychiatry 2005;17:189-97.

20 Egan M, Moride $\mathrm{Y}$, Wolfson C, Monette J. Long-term continuous use of benzodiazepines by older adults in Quebec: prevalence, incidence and risk factors. J Am Geriatr Soc 2000;48:811-6.

21 Lister RG. The amnesic action of benzodiazepines in man. Neurosci Biobehav Rev 1985;9:87-94.

22 Ghoneim MM, Mewaldt SP. Benzodiazepines and human memory: a review. Anesthesiology 1990;72:926-38.

23 Curran HV. Tranquillising memories: a review of the effects of benzodiazepines on human memory. Biol Psychol 1986;23:179-213.

24 Buffett-Jerrott SE, Stewart SH. Cognitive and sedative effects of benzodiazepine use. Curr Pharm Des 2002;8:45-58.

25 Taragano FE, Allegri RF, Krupitzki H, Sarasola DR, Serrano CM, Lon L, et al. Mild behavioral impairment and risk of dementia: a prospective cohort study of 358 patients. $J$ Clin Psychiatry 2009;70:584-92.

26 Rosenberg PB, Mielke MM, Appleby B, Oh E, Leoutsakos JM, Lyketsos CG. Neuropsychiatric symptoms in $\mathrm{MCl}$ subtypes: the importance of executive dysfunction. Int J Geriatr Psychiatry 2011;26:364-72.

27 Lyketsos CG, Lopez O, Jones B, Fitzpatrick AL, Breitner J, DeKosky S. Prevalence of neuropsychiatric symptoms in dementia and mild cognitive impairment: results from the cardiovascular health study. JAMA 2002;288:1475-83.

28 Amieva H, Le Goff M, Millet X, Orgogozo JM, Peres K, Barberger-Gateau P, et al. Prodromal Alzheimer's disease: successive emergence of the clinical symptoms. Ann Neurol 2008;64:492-8.

29 Introduction to drug utilization research. World Health Organization, 2003.

$30 \mathrm{Li} \mathrm{J}$, Wang YJ, Zhang M, Xu ZQ, Gao CY, Fang CQ, et al. Vascular risk factors promote conversion from mild cognitive impairment to Alzheimer disease. Neurology 2011;76:1485-91.

31 Ballard C, Gauthier S, Corbett A, Brayne C, Aarsland D, Jones E. Alzheimer's disease. Lancet 2011;377:1019-31.

32 Lechevallier N, Fourrier A, Berr C. [Benzodiazepine use in the elderly: the EVA Study] Rev Epidemiol Sante Publique 2003;51:317-26.

33 Fourrier A, Letenneur L, Dartigues JF, Moore N, Begaud B. Benzodiazepine use in an elderly community-dwelling population. Characteristics of users and factors associated with subsequent use. Eur J Clin Pharmacol 2001;57:419-25.

34 Quan H, Sundararajan V, Halfon P, Fong A, Burnand B, Luthi JC, et al. Coding algorithms for defining comorbidities in ICD-9-CM and ICD-10 administrative data. Med Care 2005;43:1130-9.

35 Deyo RA, Cherkin DC, Ciol MA. Adapting a clinical comorbidity index for use with ICD-9-CM administrative databases. J Clin Epidemiol 1992;45:613-9.

36 Ownby RL, Crocco E, Acevedo A, John V, Loewenstein D. Depression and risk for Alzheimer disease: systematic review, meta-analysis, and metaregression analysis. Arch Gen Psychiatry 2006:63:530-8.

37 Dotson VM, Beydoun MA, Zonderman AB. Recurrent depressive symptoms and the incidence of dementia and mild cognitive impairment. Neurology 2010;75:27-34.

38 Byers AL, Yaffe K. Depression and risk of developing dementia. Nat Rev Neurol 2011;7:323-31.

39 Van der Mussele S, Le Bastard N, Vermeiren Y, Saerens J, Somers N, Marien P, et al. Behavioral symptoms in mild cognitive impairment as compared with Alzheimer's disease and healthy older adults. Int $J$ Geriatr Psychiatry 2013;28:265-75.

40 Johansson L, Guo X, Waern M, Ostling S, Gustafson D, Bengtsson C, et al. Midlife psychological stress and risk of dementia: a 35 -year longitudinal population study. Brain 2010;133:2217-24

41 Sterniczuk R, Theou O, Rusak B, Rockwood K. Sleep disturbance is associated with incident dementia and mortality. Curr Alzheimer Res 2013:10:767-75.

42 Kang JE, Lim MM, Bateman RJ, Lee JJ, Smyth LP, Cirrito JR, et al. Amyloid-beta dynamics are regulated by orexin and the sleep-wake cycle. Science 2009;326:1005-7.

43 Ju YE, Lucey BP, Holtzman DM. Sleep and Alzheimer disease pathology-a bidirectional relationship. Nat Rev Neurol 2014;10:115-9.

44 Assem-Hilger E, Jungwirth S, Weissgram S, Kirchmeyr W, Fischer P, Barnas C. Benzodiazepine use in the elderly: an indicator for inappropriately treated geriatric depression? Int J Geriatr Psychiatry 2009;24:563-9. 
45 Lagnaoui R, Tournier M, Moride $\mathrm{Y}$, Wolfson C, Ducruet T, Begaud B, et al. The risk of cognitive impairment in older community-dwelling women after benzodiazepine use. Age Ageing 2009;38:226-8.

46 Fastbom J, Forsell $\mathrm{Y}$, Winblad B. Benzodiazepines may have protective effects against Alzheimer disease. Alzheimer Dis Assoc Dis 1998;12:14-7.

47 Swaen G, van Amelsvoort L. A weight of evidence approach to causal inference. J Clin Epidemiol 2009;62:270-7.

48 Folstein MF, Folstein SE, McHugh PR. "Mini-mental state". A practical method for grading the cognitive state of patients for the clinician. J Psychiatr Res 1975;12:189-98.

49 Ostbye T, Kristjansson B, Hill G, Newman SC, Brouwer RN, McDowell I. Prevalence and predictors of depression in elderly Canadians: the Canadian Study of Health and Aging. Chronic Dis Can 2005;26:93-9.

50 Beekman AT, Bremmer MA, Deeg DJ, van Balkom AJ, Smit JH, de Beurs E, et al. Anxiety disorders in later life: a report from the Longitudinal Aging Study Amsterdam. Int J Geriatr Psychiatry 1998;13:717-26.

51 Lemeshow S, Letenneur L, Dartigues JF, Lafont S, Orgogozo JM, Commenges D. Illustration of analysis taking into account complex survey considerations: the association between wine consumption and dementia in the PAQUID study. Personnes Ages Quid. Am J Epidemiol 1998;148:298-306.

52 Ilomaki J, Bell JS, Kauhanen J, Enlund H. Heavy drinking and use of sedative or anxiolytic drugs among aging men: an 11-year follow-up of the FinDrink study. Ann Pharmacother 2011;45:1240-7.

53 Valenzuela MJ, Sachdev P. Brain reserve and dementia: a systematic review. Psychol Med 2006;36:441-54

54 Stern Y, Gurland B, Tatemichi TK, Tang MX, Wilder D, Mayeux R. Influence of education and occupation on the incidence of Alzheimer's disease. JAMA 1994:271:1004-10.

55 Aparasu RR, Mort JR, Brandt H. Psychotropic prescription use by community-dwelling elderly in the United States. J Am Geriatr Soc 2003;51:671-7.

56 Zandstra SM, Van Rijswijk E, Rijnders CA, Van De Lisdonk EH, Bor JH, Van Weel C, et al. Long-term benzodiazepine users in family practice: differences from short-term users in mental health, coping behaviour and psychological characteristics. Fam Pract 2004;21:266-9.
57 Veronese A, Garatti M, Cipriani A, Barbui C. Benzodiazepine use in the real world of psychiatric practice: low-dose, long-term drug taking and low rates of treatment discontinuation. Eur J Clin Pharmacol 2007;63:867-73.

58 Espana J, Gimenez-Llort L, Valero J, Minano A, Rabano A, Rodriguez-Alvarez J, et al. Intraneuronal beta-amyloid accumulation in the amygdala enhances fear and anxiety in Alzheimer's disease transgenic mice. Biol Psychiatry 2010;67:513-21.

59 Tannenbaum C, Paquette A, Hilmer S, Holroyd-Leduc J, Carnahan R. A systematic review of amnestic and non-amnestic mild cognitive impairment induced by anticholinergic, antihistamine, GABAergic and opioid drugs. Drugs Aging 2012;29:639-58.

60 Petersen RC, Doody R, Kurz A, Mohs RC, Morris JC, Rabins PV, et al. Current concepts in mild cognitive impairment. Arch Neurol 2001;58:1985-92.

61 Busse A, Hensel A, Guhne U, Angermeyer MC, Riedel-Heller SG. Mild cognitive impairment: long-term course of four clinical subtypes. Neurology 2006;67:2176-85.

62 Hutchinson MA, Smith PF, Darlington CL. The behavioural and neuronal effects of the chronic administration of benzodiazepine anxiolytic and hypnotic drugs. Prog Neurobiol 1996;49:73-97.

63 Shimohama S, Taniguchi T, Fujiwara M, Kameyama M. Changes in benzodiazepine receptors in Alzheimer-type dementia. Ann Neurol 1988;23:404-6.

64 Stern Y. What is cognitive reserve? Theory and research application of the reserve concept. J Int Neuropsychol Soc 2002;8:448-60.

65 Pariente A, Dartigues JF, Benichou J, Letenneur L, Moore N, Fourrier-Reglat A. Benzodiazepines and injurious falls in community dwelling elders. Drugs Aging 2008;25:61-70.

Accepted: 04 August 2014

\section{Cite this as: BMJ 2104;349:95205}

This is an Open Access article distributed in accordance with the Creative Commons Attribution Non Commercial (CC BY-NC 3.0) license, which permits others to distribute, remix, adapt, build upon this work non-commercially, and license their derivative works on different terms, provided the original work is properly cited and the use is non-commercial. See: http://creativecommons.org/licenses/by-nc/3.0/. 


\section{Tables}

Table 1 | Elimination half life and indication for benzodiazepines reimbursed by administrative claims database in Quebec (RAMQ) in 2000-09

\begin{tabular}{|c|c|c|}
\hline Indication & Long acting (half life $\geq 20 \mathrm{~h}$ ) & Short acting (half life $<20 \mathrm{~h}$ ) \\
\hline \multirow[t]{4}{*}{ Anxiolytic } & Bromazepam (20 h) & Alprazolam (10-20 h) \\
\hline & Chlordiazepoxide $(5-30 \mathrm{~h})$ & Lorazepam (10-20 h) \\
\hline & Clobazam $(20 \mathrm{~h})$ & Oxazepam (8 h) \\
\hline & Diazepam (32-47 h) & - \\
\hline \multirow[t]{3}{*}{ Hypnotic } & Flurazepam $(120-160 \mathrm{~h})$ & Midazolam (1.5-2.5 h) \\
\hline & Nitrazepam (16-48 h) & Temazepam $(5-8 \mathrm{~h})$ \\
\hline & - & Triazolam (2 h) \\
\hline
\end{tabular}

Anticonvulsant Clonazepam $(20-60 \mathrm{~h})$ 
Table 2| Characteristics of people with Alzheimer's disease (cases) and controls (variables assessed five to up to 10 years before diagnosis). Figures are numbers (percentage) of patients

\begin{tabular}{|c|c|c|c|}
\hline Characteristics & Cases $(n=1796)$ & Controls $(n=7184)$ & $P$ value \\
\hline \multicolumn{4}{|l|}{ Sex: } \\
\hline Male & $593(33.0)$ & $2372(33.0)$ & \multirow[t]{2}{*}{ Matched } \\
\hline Female & $1203(67.0)$ & $4812(67.0)$ & \\
\hline \multicolumn{4}{|l|}{ Age (years): } \\
\hline $70-74$ & $239(13.3)$ & $956(13.3)$ & \multirow[t]{4}{*}{ Matched } \\
\hline $75-79$ & $466(26.0)$ & $1864(26.0)$ & \\
\hline $80-84$ & $565(31.5)$ & $2260(31.5)$ & \\
\hline$\geq 85$ & $526(29.3)$ & $2104(29.3)$ & \\
\hline \multicolumn{4}{|l|}{ Follow-up (years): } \\
\hline 6 & $592(33.0)$ & $2368(33.0)$ & \multirow[t]{5}{*}{ Matched } \\
\hline 7 & $583(32.5)$ & $2332(32.5)$ & \\
\hline 8 & $406(22.6)$ & $1624(22.6)$ & \\
\hline 9 & $114(6.3)$ & $456(6.3)$ & \\
\hline 10 & $101(5.6)$ & $404(5.6)$ & \\
\hline \multicolumn{4}{|l|}{ Benzodiazepine use: } \\
\hline Non-users & $902(50.2)$ & $4311(60.0)$ & \multirow[t]{2}{*}{$<0.001$} \\
\hline Users & $894(49.8)$ & $2873(40.0)$ & \\
\hline \multicolumn{4}{|c|}{ Benzodiazepine density exposure (No of prescribed daily doses): } \\
\hline Non-users & $902(50.2)$ & $4311(60.0)$ & \multirow[t]{4}{*}{$<0.001$} \\
\hline $1-90$ & $234(13.0)$ & $1051(14.6)$ & \\
\hline $91-180$ & $70(3.9)$ & $257(3.6)$ & \\
\hline$>180$ & $590(32.9)$ & $1565(21.8)$ & \\
\hline \multicolumn{4}{|l|}{ Benzodiazepine elimination half life: } \\
\hline Non-users & $902(50.2)$ & $4311(60.0)$ & \multirow[t]{3}{*}{$<0.001$} \\
\hline Short half life $(<20 \mathrm{~h})$ & $585(32.6)$ & $1996(27.8)$ & \\
\hline Long half life ( $\geq 20 \mathrm{~h})$ & $309(17.2)$ & $877(12.2)$ & \\
\hline High blood pressure ${ }^{*} \dagger$ & $1155(64.3)$ & $4508(62.8)$ & 0.22 \\
\hline Myocardial infarction* & $61(3.4)$ & $330(4.6)$ & 0.03 \\
\hline Stroke* & $125(7.0)$ & $416(5.8)$ & 0.06 \\
\hline Hypercholesterolaemia* $\dagger$ & $376(20.9)$ & $1187(16.5)$ & $<0.001$ \\
\hline Diabetes mellitus ${ }^{*} \dagger$ & $336(18.7)$ & $1299(18.1)$ & 0.54 \\
\hline Comorbidity $\ddagger$ & $719(40.0)$ & $2738(38.1)$ & 0.13 \\
\hline Platelet inhibitors or oral anticoagulants $\dagger$ & $138(7.7)$ & $630(8.8)$ & 0.14 \\
\hline Anxiety $^{*}$ & $384(21.4)$ & $1083(15.1)$ & $<0.001$ \\
\hline Depressive symptoms* & $52(2.9)$ & $172(2.4)$ & 0.22 \\
\hline Insomnia* & $72(4.0)$ & $229(3.2)$ & 0.08 \\
\hline
\end{tabular}

${ }^{*}$ Evaluated by ICD-9 diagnosis.

†Evaluated by drug claims.

$\ddagger$ At least one medical ICD-9 diagnosis of chronic pulmonary disease, rheumatic disease, peptic ulcer disease, liver disease, hemiplegia or paraplegia, renal disease, malignancy or metastatic solid tumor, HIV/AIDS, registered. 
Table 3| Risk of Alzheimer's disease associated with benzodiazepine use (variables assessed five to up to 10 years before diagnosis) in people with Alzheimer's disease (cases) and controls

\begin{tabular}{|c|c|c|c|c|c|}
\hline & \multirow{2}{*}{$\begin{array}{c}\text { No }(\%) \text { of cases } \\
\quad(n=1796)\end{array}$} & \multirow{2}{*}{$\begin{array}{c}\text { No }(\%) \text { of controls } \\
(n=7184)\end{array}$} & \multirow{2}{*}{$\begin{array}{l}\text { Univariable odds ratio } \\
\qquad(95 \% \mathrm{Cl})^{\star}\end{array}$} & \multicolumn{2}{|c|}{ Multivariable odds ratio $(95 \% \mathrm{Cl})$} \\
\hline & & & & Model $1^{*} \dagger$ & Model $2^{*} \ddagger$ \\
\hline \multicolumn{6}{|c|}{ Benzodiazepine ever use: } \\
\hline Non-users & $902(50.2)$ & $4311(60.0)$ & 1.00 & 1.00 & 1.00 \\
\hline Users & $894(49.8)$ & $2873(40.0)$ & $1.52(1.37$ to 1.69$)$ & 1.51 (1.36 to 1.69$)$ & $1.43(1.28$ to 1.60$)$ \\
\hline \multicolumn{6}{|c|}{ Benzodiazepine density exposure (No of prescribed daily doses): } \\
\hline Non-users & $902(50.2)$ & $4311(60.0)$ & 1.00 & 1.00 & 1.00 \\
\hline $1-90$ & $234(13.0)$ & $1051(14.6)$ & $1.08(0.92$ to 1.27$)$ & 1.09 (0.92 to 1.28$)$ & $1.05(0.89$ to 1.24$)$ \\
\hline $91-180$ & $70(3.9)$ & $257(3.6)$ & 1.33 (1.01 to 1.75$)$ & $1.32(1.01$ to 1.74$)$ & $1.28(0.97$ to 1.69$)$ \\
\hline$>180$ & $590(32.9)$ & $1565(21.8)$ & 1.85 (1.63 to 2.09$)$ & 1.84 (1.62 to 2.08$)$ & 1.74 (1.53 to 1.98$)$ \\
\hline \multicolumn{6}{|c|}{ Benzodiazepine elimination half life: } \\
\hline Non-users & $902(50.2)$ & $4311(60.0)$ & 1.00 & 1.00 & 1.00 \\
\hline Short half life $(<20 \mathrm{~h})$ & $585(32.6)$ & $1996(27.8)$ & $1.43(1.27$ to 1.61$)$ & $1.43(1.27$ to 1.61$)$ & $1.37(1.21$ to 1.55$)$ \\
\hline Long half life $(\geq 20 \mathrm{~h})$ & $309(17.2)$ & $877(12.2)$ & $1.72(1.48$ to 1.99$)$ & $1.70(1.46$ to 1.98$)$ & 1.59 (1.36 to 1.85$)$ \\
\hline
\end{tabular}

*Matched for age, sex, and follow-up length.

†Adjusted for high blood pressure (diagnosis or treatment), myocardial infarction (diagnosis), stroke (diagnosis), platelet inhibitors or oral anticoagulant treatment, diabetes mellitus (diagnosis or treatment), hypercholesterolaemia (diagnosis or treatment), comorbidity (diagnosis).

‡Further adjusted for anxiety, depression, and insomnia diagnosis. 


\section{Figure}

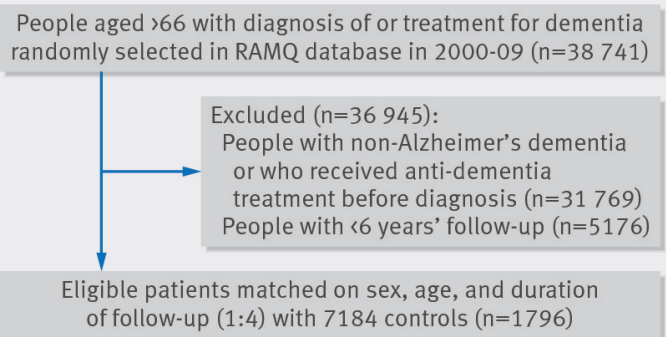

Selection of people to include as cases in study of benzodiazepine use and risk of Alzheimer's disease 